\title{
Antioxidative capacity of hydrolyzed rapeseed cake extract and oxidative stability of fish oil-in-water emulsion added with the extract
}

\author{
A-Young Lee, Jeung-Hee Lee* \\ Department of Food and Nutrition, Daegu University, Gyeongsan 38453, Korea
}

\begin{abstract}
Rapeseed cake was extracted with $80 \%$ ethanol and then fractionated with $\mathrm{H}_{2} \mathrm{O}$ (fraction I) as well as with $30 \%$ (II), 50\% (III), 70\% (IV), and 100\% ethanol (V). Total phenolic content (TPC), 2,2-diphenyl-1-picrylhydrazyl (DPPH) radical scavenging activity, ferric-reducing antioxidant potential, and Trolox equivalent antioxidant capacity were in the order of fractions II $>$ III $>$ I $>$ IV $>$ V. The three fractions with high antioxidant activities and TPC (I, II, and III) were pooled and hydrolyzed by $\mathrm{NaOH}$ solution, resulting in $18.97 \mathrm{mg}$ sinapic acid/g hydrolyzed extract and 21- and 2.2-fold increases in TPC and DPPH radical scavenging activity, respectively. Hydrolyzed rapeseed cake extracts $(200,500$, and $1,000 \mathrm{ppm})$ and catechin $(200 \mathrm{ppm})$ as a comparison were added to $10 \%$ fish oil-in-water emulsion, and their effects on oxidative stability were investigated by measuring hydroperoxide values (PV) during refrigerated storage. PVs were significantly lower in the emulsions with added hydrolyzed extract as compared to the control $(p<0.05)$ and significantly decreased with increasing extract concentration $(p<0.05)$ over a period of 29 days. The emulsion added with hydrolyzed extract showed higher PV than that added catechin at the same concentration $(200 \mathrm{ppm})$ during 13-22 days $(p<0.05)$, but after then, the PV was not significantly different $(p>0.05)$. This study indicates that hydrolyzed rapeseed cake extract rich in sinapic acid may inhibit oxidation in a fish oil-in-water emulsion in a concentration-dependent manner.
\end{abstract}

Key words : emulsion, fish oil, oxidative stability, rapeseed cake, sinapic acid

\section{Introduction}

Rapeseed (Brassica napus L.) is used in the production of animal feed, bio diesel, and vegetable oil for human consumption since it has a high yield per unit area and high oil content (1). Traditional rapeseed contains glucosinolate and erucic acid. Glucosinolate contributes a bitter taste and causes goiter when consumed in high amounts (2). Erucic acid constitutes about $58 \%$ of the total fatty acid content of rapeseed and causes heart disease and chronic myocardiopathy at high amounts (3). To overcome such disadvantages, Canada, the United States, and the European countries have developed rapeseed varieties with lower

*Corresponding author. E-mail : jeunghlee@daegu.ac.kr Phone : 82-53-850-6836, Fax : 82-53-850-6839

Received 20 January 2017; Revised 3 March 2017; Accepted 14 March 2017.

Copyright (c) The Korean Society of Food Preservation. All rights reserved. contents of glucosinolate and erucic acid, resulting in canola oil or low-erucic acid rapeseed oil in the market (4).

Rapeseed cake, a byproduct of oil extraction from rapeseed, is composed of $11.4 \%$ water, $2.8 \%$ crude fat, $36.1 \%$ crude protein, and $6.3 \%$ crude ash (5). Rapeseed cake also contains natural antioxidants, known as phenolic compounds, and major phenolics are sinapic acid derivatives. Sinapic acid constitutes over $73 \%$ of the free phenolic acid content of rapeseed cake, whereas sinapine (choline ester of sinapic acid), as the main phenolic compound, constitutes about $80 \%$ of the total phenolic content along with 1-O- $\beta-D$ glucopyranosyl sinapate (sinapoyl glucose) and vinylsyringol (a decarboxylated sinapic acid) (6,7). Thiyam et al. (8) previously reported phenolic compounds in rapeseed cake with 2,2-diphenyl-1-picrylhydrazyl (DPPH) radical scavenging activity in the order of sinapic acid > sinapoyl glucose $>$ sinapine, suggesting that structural features, such as esterification of sinapic acid with a choline or glucose moiety could reduce antioxidative activities. Sinapic acid is known 
to be a more effective antioxidant than sinapine during lipid oxidation. Sinapine was shown to be slightly prooxidatve or have no inhibitory effect on hydroperoxide formation while sinapic acid was shown to have a higher antioxidative capacity at higher concentrations (9).

Fish oil contains large amounts of $\omega-3$ fatty acids, such as eicosapentaenoic acid (EPA) and docosahexaenoic acid (DHA). DHA plays a significant role in brain development due to its beneficial effects on neurogenesis, neurotransmission, and protection against oxidative stress (10). EPA has lowering effects on blood triacylglycerol and LDL-cholesterol concentrations and prevents atherosclerosis and other heart diseases. However, oils and foods containing large amounts of $\omega-3$ fatty acids can be easily oxidized through processing, storage, and distribution, resulting in production of various radicals and peroxides. Furthermore, their decomposition products can cause off-flavors that diminish consumer preferences for these foods and their original qualities. Many foods exist as an oil-in-water emulsion. To utilize fish oil in an emulsion-based food, addition of antioxidants, such as phenolic compounds is needed to increase oxidative stability (11).

In the present study, defatted rapeseed cake was extracted with $80 \%$ ethanol and this crude extract was fractionated with solvents having different polarities. The total phenolic content and antioxidant capacity of each fraction were assessed, and three fractions with high antioxidant capacities were combined and hydrolyzed using $\mathrm{NaOH}$. The antioxidant capacity of hydrolyzed extract was compared with crude extract, and then the effect of hydrolyzed extract on oxidative stability in fish oil-in-water emulsion was investigated.

\section{Materials and Methods}

\section{Materials}

Rapeseed cake from Hanla cultivar was obtained from the Rural Development Administration (RDA) (Junju, Korea) in 2011 and stored at $-20^{\circ} \mathrm{C}$. Fish oil was provided from Neomega Co., Ltd. (Deajeon, Korea). Sinapic acid, catechin, 6-hydroxy2,5,7,8-tetramethylchroman-2-carboxylic acid (Trolox), and 1,1,3,3 - tetraethoxypropane were purchased from Sigma-Aldrich Co., Ltd. (St. Louis, MO, USA). 2,2'-azinobis-3ethylbenzothiazoline-6-sulfonic acid (ABTS), 2,4,6-tripyridyls-triazine (TPTZ), Folin-ciocalteu's phenol reagent, DPPH, barium chloride, ferrous sulfate ammonium thiocyanate, sodium azide, hydrogen peroxide, and Tween 20 (Polyoxyethylene sorbitan monolaurate) were purchased from
Sigma-Aldrich Co., Ltd.. All solvents were HPLC grade and obtained from Fisher Scientific Co., Ltd. (Norcross, GA, USA).

\section{Extraction of phenolic compounds from rapeseed} cake

Rapeseed cake was first extracted with hexane to remove the small quantity of fat residue. Phenolic compounds were then extracted from defatted rapeseed cake with $50 \mathrm{~mL}$ of $80 \%(\mathrm{v} / \mathrm{v})$ ethanol at $55^{\circ} \mathrm{C}$ and $135 \mathrm{rpm}$ for $1 \mathrm{~h}$ in a shaking water bath, centrifuged at $730 \mathrm{~g}$ for $5 \mathrm{~min}$, and then filtered. Extraction was repeated two more times. Supernatants were combined, and water was removed by passing through an anhydrous sodium sulfate column. Ethanol was evaporated by a rotary vacuum evaporator at $60^{\circ} \mathrm{C}$, after which residual ethanol was removed under nitrogen. The prepared crude extract was stored at $-20^{\circ} \mathrm{C}$ until further investigation.

\section{Solvent fractionation of crude extract}

Rapeseed cake crude extract (400 mg) was re-dissolved in $80 \%$ ethanol ( $4 \mathrm{~mL})$, after which $0.5 \mathrm{~mL}$ was loaded onto a syringe column $(5 \mathrm{~mL})$ packed with $1.5 \mathrm{~g}$ of Diaion HP-20 (Sigma-Aldrich) and covered with sea sand. After adsorption for $1 \mathrm{~h}$, fractionation was carried out using solvents with different polarities in $\mathrm{H}_{2} \mathrm{O}$ (I) and $30 \%$ (II), $50 \%$ (III), $70 \%$ (IV), and $100 \%$ ethanol (V), respectively. The elution solvent (each $6 \mathrm{~mL}$ ) was passed through the syringe column by reduced pressure with a vacuum manifold (Visiprep ${ }^{\mathrm{TM}}$, Supelco Inc., Bellefonte, PA, USA).

\section{Total phenolic content (TPC)}

The TPC of each fraction was determined according to the method of Thiyam et al. (8) with slight modification. Fractions $\mathrm{I}-\mathrm{V}(0.5 \mathrm{~mL}), 0.45 \mathrm{~mL}$ of distilled water, and 0.5 $\mathrm{mL}$ of Folin-Ciocalteu reagent were mixed together. After $3 \mathrm{~min}, 1 \mathrm{~mL}$ of $1 \mathrm{~N} \mathrm{Na}_{2} \mathrm{CO}_{3}$ was added and the mixture was in the dark for $1 \mathrm{~h}$, after which absorbance was measured at $725 \mathrm{~nm}$. A standard curve was prepared with sinapic acid, and TPC was expressed as $\mathrm{mg}$ of sinapic acid equivalents $(\mathrm{SAE}) / \mathrm{mL}$ fraction.

\section{Antioxidative capacities of crude extract from rapeseed cake}

The DPPH radical scavenging activities of the fractions were determined by mixing $0.2 \mathrm{~mL}$ of each crude extract fraction (I-V), $1.8 \mathrm{~mL}$ of ethanol, and $2.5 \mathrm{~mL}$ of DPPH reagent $(0.15 \mathrm{mM})$ (12). After $30 \mathrm{~min}$ in the dark, absorbance was measured at $516 \mathrm{~nm}$ with a spectrophotometer. DPPH radical 
scavenging activity (RSA) was calculated using the following equation:

$$
\begin{array}{r}
\mathrm{DPPH} \text { radical scavenging activity }(\mathrm{RSA}, \%) \\
=\left[\left(\mathrm{Abs}_{\text {blank }}-\mathrm{Abs}_{\text {fraction }}\right) / \mathrm{Abs}_{\text {fraction }}\right] \times 100
\end{array}
$$

Ferric reducing antioxidant potential (FRAP) assay was performed according to the method of Wong et al. (13) with slight modification. FRAP reagent was prepared by mixing $10 \mathrm{mM}$ TPTZ in $40 \mathrm{mM} \mathrm{HCl}, 20 \mathrm{mM}$ ferric chloride solution, and $300 \mathrm{mM}$ acetate buffer ( $\mathrm{pH}$ 3.6) at a 1:1:10 ratio (v/v/v). Fractions $(150 \mu \mathrm{L})$ were added to FRAP reagent $(5 \mathrm{~mL})$, vortexed, and reacted for $4 \mathrm{~min}$ at $35^{\circ} \mathrm{C}$. Absorbance was then measured at $593 \mathrm{~nm}$. A standard curve was generated with ascorbic acid, and FRAP values were expressed as mg of ascorbic acid equivalent $/ \mathrm{mL}$ of rapeseed cake extract fraction.

To determine the trolox equivalent antioxidant capacities (TEACs) of the fractions, ABTS radicals were generated by mixing $7 \mathrm{mM}$ ABTS and $2.45 \mathrm{mM}$ potassium persulfate $(1: 0.5, \mathrm{v} / \mathrm{v})(14)$. Solution was incubated at room temperature in the dark for 12-16 h, after which ABTS radical solution was diluted with ethanol until an absorbance of $0.7 \pm 0.02$ at $734 \mathrm{~nm}$ was achieved. Fraction $(100 \mu \mathrm{L})$ was mixed with ABTS radical solution $(5 \mathrm{~mL})$ in a test tube and left for $6 \mathrm{~min}$. Absorbance was then measured at $734 \mathrm{~nm}$. Trolox was used as a standard, and results were expressed as $\mathrm{mg}$ of Trolox equivalent (TE)/mL of crude extract fraction.

$\mathrm{NaOH}$-mediated hydrolysis of fractions obtained from rapeseed cake crude extract

Hydrolysis of fractions obtained from crude extract was performed according to the method of Vuorela et al. (15) with slight modification. The combined fractions (I, II, and III) were hydrolyzed with $4 \mathrm{M} \mathrm{NaOH}$ solution by stirring for $90 \mathrm{~min}$ at $300 \mathrm{rpm}$ in an Erlenmeyer flask. After hydrolysis, $37 \% \mathrm{HCl}$ solution was added until a $\mathrm{pH}$ level was reached to 2 . Phenolic acids were released when the $\mathrm{pH}$ was lower than 2, and ethyl acetate:diethyl ether (1:1, v/v) was added to extract phenolic acids from the hydrolyzed reaction mixture in a separatory funnel. The ethyl acetate:diethyl ether layer was separated, dehydrated with an anhydrous sodium sulfate column, and evaporated with a rotary vacuum evaporator following $\mathrm{N}_{2}$ flushing for dryness. Finally, hydrolyzed extract containing highly concentrated phenolic acids, mostly sinapic acid, was obtained.
Quantification of sinapic acid content by HPLC

Quantification of sinapic acid content was performed by reversed-phase high performance liquid chromatography (RP-HPLC). The $20 \mu \mathrm{L}$ sample was injected into an HPLC equipped with a UV detector $(325 \mathrm{~nm})$ and NovaPak ${ }^{\circledR} \mathrm{C} 18$

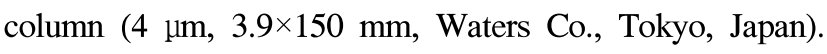
Gradient elution was performed using methanol as solvent A and $0.02 \mathrm{M}$ phosphate buffer/methanol $(75: 25, \mathrm{v} / \mathrm{v})$ as solvent $\mathrm{B}$ with the following gradient: hold $\mathrm{A}: \mathrm{B}=5: 95 \mathrm{(v/v)}$ ratio for $15 \mathrm{~min}, 35: 65$ for $20 \mathrm{~min}$, and 95:5 for the last $17 \mathrm{~min}$. The flow rate of the mobile phase was set at 0.6 $\mathrm{mL} / \mathrm{min}$. Sinapic acid was used as a standard for quantification.

\section{Fatty acid composition of fish oil}

The fatty acid composition of fish oil was analyzed using a gas chromatograph (GC, Agilent 6890, Avondale, PA, USA) equipped with a flame ionization detector and $\mathrm{SP}^{\mathrm{TM}}-2560$ column (biscyanopropyl polysiloxane, $100 \mathrm{~m} \times 0.25 \mathrm{~nm} \times 0.2$ $\mu \mathrm{m}$ film thickness, Supelco Co., St. Louis, MO, USA) following the modified method of Gan et al. (11).

\section{Preparation of fish oil-in-water emulsion}

Tween 20 (0.3\%, Polyoxyethylene sorbitan monolaurate) was dissolved in Tris-bis buffer $(\mathrm{pH} \mathrm{7.0)}$ by sonication for $1 \mathrm{~h}$. The $10 \%(\mathrm{w} / \mathrm{w})$ fish oil-in-water emulsion was prepared by pre-mixing $10 \mathrm{~g}$ of fish oil and $90 \mathrm{~mL}$ of buffer containing $0.02 \%$ sodium azide (as a preservative) with Silverson mixer (L4RT, Silverson Machines Ltd., Chesham, UK) for $2 \mathrm{~min}$ at 5,000 rpm, followed by a Microfludizer (M-110Y, Microfludics, Newton, MA, USA) at 3,000 PRI. The hydrolyzed extracts $(0,200,500$, and 1,000 ppm) were added to the fish oil-in-water emulsion. Emulsion with 200 ppm of catechin was also prepared for comparison with hydrolyzed rapeseed cake extract.

Oxidative stabilities of fish oil-in-water emulsions Oxidation of each emulsion was carried out at $35^{\circ} \mathrm{C}$ for 30 days. To measure hydroperoxide values, $0.144 \mathrm{M}$ barium chloride in $0.4 \mathrm{M} \mathrm{HCl}$ and $0.144 \mathrm{M}$ ferrous sulfate (freshly made, $1: 1=\mathrm{v} / \mathrm{v}$ ) were mixed and centrifuged for $5 \mathrm{~min}$ at $1,143 \times g$ (11). The supernatant and $4 \mathrm{M}$ ammonium thiocyanate $(1: 1, \mathrm{v} / \mathrm{v})$ were mixed to prepare the reagent. In a separate test tube, $3 \mathrm{~mL}$ of methanol/butanol $(2: 1, \mathrm{v} / \mathrm{v})$, $20 \mu \mathrm{L}$ of emulsion, and $30 \mu \mathrm{L}$ of reagent were mixed, after which absorbance was measured at $510 \mathrm{~nm}$ after $20 \mathrm{~min}$. Hydroperoxide value was quantified by the obtained standard 
curve with hydrogen peroxide $\left(\mathrm{H}_{2} \mathrm{O}_{2}\right)$, and $\mathrm{PV}$ was expressed as meq of $\mathrm{H}_{2} \mathrm{O}_{2} / \mathrm{L}$ emulsion

\section{Statistical analysis}

Analysis of variance (ANOVA) was performed using the Statistical Analysis System (SAS) 9.2 (SAS Institute Inc., Cary, NC, USA). Statistical significance of means were analyzed by student $t$-test or Duncan's multiple range test at $\mathrm{p}<0.05$.

\section{Results and Discussion}

\section{Antioxidant capacities of crude extract}

TPC of crude extract was $33.03 \mathrm{mg} / \mathrm{g}$ while DPPH radical scavenging activity was $42.64 \%$ (Table 1). According to Kim and $\mathrm{Na}$ (16), TPC of rapeseed cake extracts using water, hot water, methanol, and acetone were 10.0, 32.1, 49.6, and $40.1 \mathrm{mg} / \mathrm{g}$, respectively. Teh and Birch (17) also reported that the TPC of canola cake extract with methanol: acetone:water $(7: 7: 6, \mathrm{v} / \mathrm{v} / \mathrm{v})$ after ultrasonic treatment was $19.72-22.05 \mathrm{mg} / \mathrm{g}$. The main phenolic compounds of rapeseed cake are sinapine, sinapoyl glucose, and sinapic acid. Sinapine, the choline ester of sinapic acid, is the main phenolic ester and constitutes about $80 \%$ of total phenolics while sinapoyl glucose is the glycoside of sinapic acid as a minor derivative (18). Sinapic acid is a free phenolic acid and is known to be a potent radical scavenger $(6,9)$.

Crude extract was then fractionated based on its polarities in $\mathrm{H}_{2} \mathrm{O}$ (I), 30\% ethanol (II), 50\% ethanol (III), 70\% ethanol (IV), and $100 \%$ ethanol (V). The highest TPC was detected in fraction II $(0.47 \mathrm{mg}$ of SAE $/ \mathrm{mL})$. TPCs were in the order of fractions II > III $>$ I $>$ IV $>$ V, and no significant difference was detected between fractions II and III ( $p>0.05)$ (Table 2). The antioxidant capacity of each fraction was determined based on DPPH RSA, FRAP, and TEAC, and the results are shown in Table 2. DPPH RSA was the highest in fraction II (88.34\%) while fractions III and I had the second and third highest RSAs ( $86.33 \%$ and $85.22 \%$, respectively). DPPH RSAs were not significantly different among fractions I, II, and III ( $p>0.05)$, whereas values for fractions IV and V were significantly lower $(\mathrm{p}<0.05)$. DPPH RSAs of rapeseed cake extract fractions in the present study were similar to those of Korean rapeseed extract using the same fractionation method in the order of $30 \%>50 \%>\mathrm{H}_{2} \mathrm{O}>70 \%>100 \%$ ethanol (19). The FRAP and TEAC results for each fraction were similar to the DPPH RSAs. Fractions I, II, and III appeared to have higher FRAP and TEACs than fractions

Table 1. Contents of total phenolics and sinapic acid and DPPH radical scavenging activity of crude extract and hydrolyzed extract obtained from rapeseed cake

\begin{tabular}{cccc}
\hline Rapeseed cake extracts & $\begin{array}{c}\text { Total phenolic content } \\
\left(\mathrm{SAE}^{1)} \mathrm{mg} / \mathrm{g}\right)\end{array}$ & $\begin{array}{c}\text { Sinapic acid content } \\
(\mathrm{mg} / \mathrm{g})^{2}\end{array}$ & $\begin{array}{c}\text { DPPH free radical } \\
\text { scavenging activity }(\%)\end{array}$ \\
\hline Crude extract ${ }^{3)}$ & $\left.33.03 \pm 6.88^{\mathrm{b5}}\right)$ & $0.07 \pm 0.01^{\mathrm{b}}$ & $42.64 \pm 2.44^{\mathrm{b}}$ \\
Hydrolyzed extract ${ }^{4}$ & $693.92 \pm 28.34^{\mathrm{a}}$ & $18.97 \pm 0.57^{\mathrm{a}}$ & $94.26 \pm 0.38^{\mathrm{a}}$ \\
\hline
\end{tabular}

\footnotetext{
${ }^{1)}$ SAE, sinapic acid equivalent.

${ }^{2)}$ Sinapic acid contents (mg/g) of crude and hydrolyzed extracts after concentration with vacuum evaporator and dried under nitrogen.

${ }^{33}$ Rapeseed cake extract with $80 \%$ ethanol.

${ }^{4} \mathrm{NaOH}$-mediated hydrolyzed extract of combined fractions eluted with $\mathrm{H}_{2} \mathrm{O}$ (I), 30\% ethanol (II) and 50\% ethanol (III) from crude extract

${ }^{5) a-b}$ Means with different letters within the same column are significantly different at $\mathrm{p}<0.05$ by student $t$-test $(\mathrm{n}=2)$.
}

Table 2. Antioxidative capacities of five different fractions from crude extract of rapeseed cake

\begin{tabular}{lccccc}
\hline & \multicolumn{4}{c}{ Fractions } \\
\cline { 2 - 6 } & I & $\begin{array}{c}\text { II } \\
\left(\mathrm{H}_{2} \mathrm{O}\right)\end{array}$ & $\begin{array}{c}\text { III } \\
(30 \% \text { ethanol })\end{array}$ & $\begin{array}{c}\text { IV ethanol) } \\
(70 \% \text { ethanol) }\end{array}$ & $\begin{array}{c}\text { V } \\
(100 \% \text { ethanol) }\end{array}$ \\
\hline TPC (SAE, mg/mL) & $0.25 \pm 0.07^{\mathrm{b} 4)}$ & $0.47 \pm 0.08^{\mathrm{a}}$ & $0.36 \pm 0.03^{\mathrm{ab}}$ & $0.10 \pm 0.65^{\mathrm{c}}$ & $0.05 \pm 0.01^{\mathrm{c}}$ \\
DPPH radical scavenging activity (\%) & $85.22 \pm 0.11^{\mathrm{a}}$ & $88.34 \pm 1.79^{\mathrm{a}}$ & $86.33 \pm 1.05^{\mathrm{a}}$ & $70.51 \pm 2.84^{\mathrm{b}}$ & $52.45 \pm 0.21^{\mathrm{c}}$ \\
FRAP (ascorbic acid equivalent, mg/mL) & $0.12 \pm 0.00^{\mathrm{c}}$ & $0.19 \pm 0.00^{\mathrm{a}}$ & $0.17 \pm 0.02^{\mathrm{b}}$ & $0.09 \pm 0.00^{\mathrm{d}}$ & $0.07 \pm 0.00^{\mathrm{d}}$ \\
TEAC (Trolox equivalent, $\mathrm{mg} / \mathrm{mL})^{3)}$ & $0.27 \pm 0.04^{\mathrm{b}}$ & $0.44 \pm 0.06^{\mathrm{a}}$ & $0.37 \pm 0.04^{\mathrm{a}}$ & $0.15 \pm 0.02^{\mathrm{c}}$ & $0.06 \pm 0.02^{\mathrm{c}}$ \\
\hline
\end{tabular}

\footnotetext{
${ }^{1)} \mathrm{SAE}$, sinapic acid equivalent.

${ }^{2)} \mathrm{FRAP}$, ferric reducing antioxidant potential.

${ }^{3)} \mathrm{TEAC}$, trolox equivalent antioxidant capacities

${ }^{4) a-d}$ Means with different letters within the same row are significantly different at $\mathrm{p}<0.05$ by Duncan's multiple range test $(n=2)$.
} 
IV and V. Specifically, the FRAP of fraction II was higher than that of fraction III $(\mathrm{p}<0.05)$, whereas no significant difference in TEAC was observed $(p>0.05)$. These results indicate that phenolic compounds contributed to the antioxidant capacity of each fraction.

$\mathrm{NaOH}$-mediated hydrolysis of fractions obtained from rapeseed cake crude extract

Three fractions enriched in TPC (fractions I, II, and III) were combined and hydrolyzed with $\mathrm{NaOH}$. Sinapic acid and sinapine from crude extract and hydrolyzed extract were separated and quantified by HPLC, and the chromatogram shows that sinapine identified in crude extract disappeared in hydrolyzed extract (Fig. 1) since $\mathrm{NaOH}$ breaks the esterlinkage in sinapine and liberates sinapic acid and choline during hydrolysis, and the released sinapic acids were extracted using ethyl acetate:diethyl ether and then concentrated in the present study. Sinapic acid content was $0.07 \mathrm{mg} / \mathrm{g}$ in crude extract while the content increased up to $18.97 \mathrm{mg} / \mathrm{g}$ in hydrolyzed extract (Table 1).
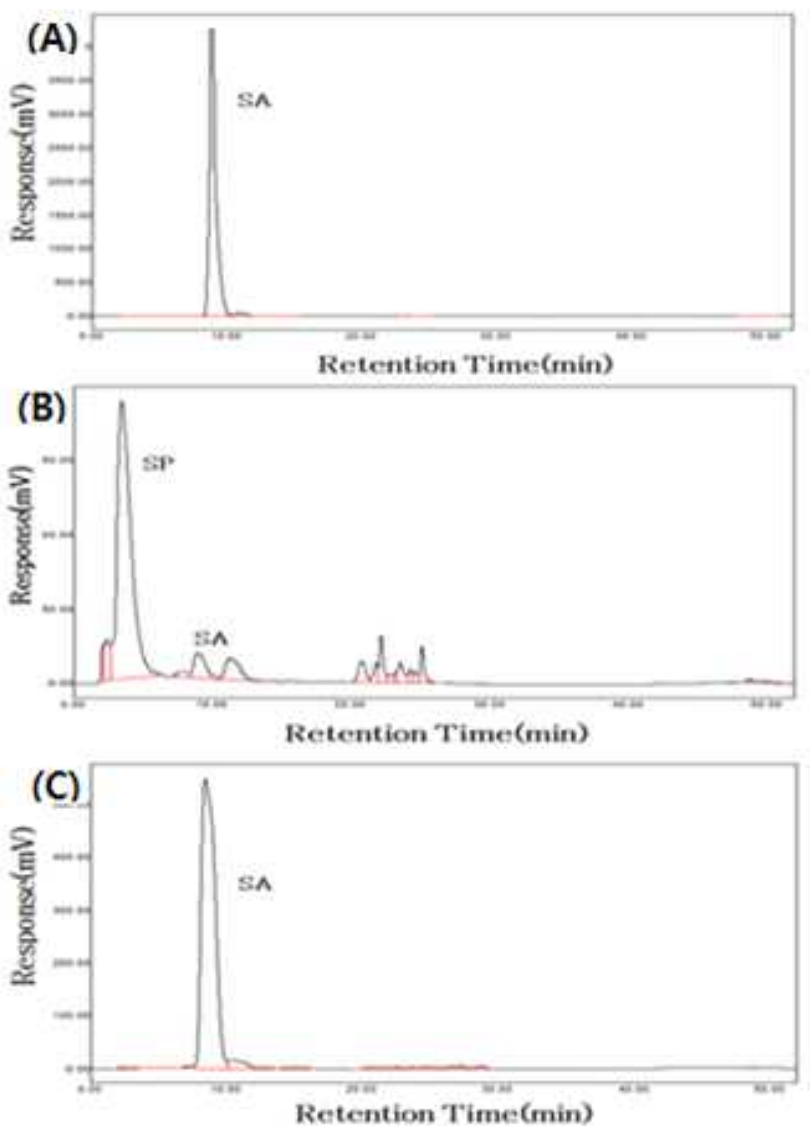

Fig. 1. Reversed-phase HPLC chromatograms of (A) standard sinapic acid, (B) crude extract of rapeseed cake with $80 \%$ ethanol, and (C) $\mathrm{NaOH}-$ mediated hydrolyzed extract. Sinapic acid (SA), Sinapine (SP).
After hydrolysis, DPPH RSA and TPC were increased by 2.2-fold and 21-fold in hydrolyzed extract compared with crude extract (Table 1). Sinapine has been reported to have lower antioxidant potential than other phenolic compounds such as sinapic acid and sinapoyl glucose in rapeseed cake (8). In addition, sinapic acid was shown to be a more effective antioxidant against lipid oxidation than sinapine by inhibiting formation of hydroperoxide (9). Although sinapic acid and sinapine possess the same substitution of one hydroxyl and two methoxyl groups on their phenol rings, the side chain is structurally different having - $\mathrm{CHCHCOOH}$ in sinapic acid and $-\mathrm{CH}=\mathrm{CHCOOCH}_{2} \mathrm{CH}_{2} \mathrm{~N}\left(\mathrm{CH}_{3}\right)_{3}$ in sinapine, and the esterified side chains (choline ester) may explain their different radical scavenging activities (20). Kikuzaki et al. (21) reported that DPPH radical scavenging activity is higher in phenolic acids than in their ester derivatives.

Oxidative stability of fish oil-in-water emulsion

Fish oil consisted of $32.29 \% \omega-3$ fatty acids, such as DHA and EPA (Table 3), which are highly susceptible to lipid oxidation and generate secondary oxidation products that

Table 3 Fatty acid composition (area\%) of fish oil

\begin{tabular}{|c|c|}
\hline Fatty acids & Composition \\
\hline $\mathrm{C} 12: 0$ & $0.04 \pm 0.01$ \\
\hline $\mathrm{C} 14: 0$ & $4.37 \pm 0.02$ \\
\hline $\mathrm{C} 14: 1$ & $0.11 \pm 0.01$ \\
\hline $\mathrm{C} 16: 0$ & $27.19 \pm 0.03$ \\
\hline C16:1 & $6.71 \pm 0.09$ \\
\hline $\mathrm{C} 18: 0$ & $6.48 \pm 0.01$ \\
\hline $\mathrm{C} 18: 1$ & $0.17 \pm 0.01$ \\
\hline $\mathrm{C} 18: 1(\omega-9)$ & $16.64 \pm 0.24$ \\
\hline $\mathrm{C} 18: 2(\omega-6)$ & $1.49 \pm 0.10$ \\
\hline $\mathrm{C} 20: 0$ & $0.53 \pm 0.04$ \\
\hline $\mathrm{C} 18: 3(\omega-6)$ & $0.26 \pm 0.01$ \\
\hline $\mathrm{C} 20: 1$ & $0.99 \pm 0.13$ \\
\hline $\mathrm{C} 18: 3(\omega-3)$ & $0.45 \pm 0.04$ \\
\hline $\mathrm{C} 20: 2$ & $0.76 \pm 0.40$ \\
\hline $\mathrm{C} 20: 3(\omega-6)$ & $0.69 \pm 0.54$ \\
\hline $\mathrm{C} 20: 4$ & $1.21 \pm 1.21$ \\
\hline C20:5 (EPA, $\omega-3)$ & $5.11 \pm 0.01$ \\
\hline C22:6 (DHA, $\omega-3)$ & $26.72 \pm 0.33$ \\
\hline Saturated fatty acids & $38.63 \pm 0.10$ \\
\hline Unsaturated fatty acids & $61.36 \pm 0.10$ \\
\hline$\omega-3$ fatty acids & $32.29 \pm 0.39$ \\
\hline
\end{tabular}


promote serious problems with respect to food quality and consumer health (22). In this study, oxidation status of the fish oil-in-water emulsion with hydrolyzed extract was evaluated based on hydroperoxide values (PV) as the primary oxidation index. Many foods exist as an oil-in-water emulsion, and the behavior of antioxidants in emulsions depends on chemical structure. Generally, phenolic compounds are plant secondary metabolites possessing one common structural feature of an aromatic ring with at least one hydroxyl substituent. Therefore, phenols inactivate free radicals by hydrogen atom transfer and single electron transfer mechanisms as well as by a transition metal chelation mechanism (23). As a phenolic acid, the chemical structure of sinapic acid improves antioxidant efficiency due to the presence of two methoxy $\left(-\mathrm{OCH}_{3}\right)$ substitutions at the ortho position, and the presence of a $\mathrm{CH}=\mathrm{CH}-\mathrm{COOH}$ group that improves stabilization of the phenol ring in the molecule (24).

In Fig. 2, PV of the control emulsion was the highest among emulsion groups during the storage period $(p<0.05)$. As the concentration of hydrolyzed rapeseed cake extract in the emulsion increased from 200 to 1,000 ppm, PV significantly decreased $(p<0.05)$. On day 3 , PVs of the oil-in-water emulsions at any concentration (200, 500, and 1,000 ppm) of hydrolyzed extract were significantly lower (1.24-6.12 meq/L emulsion) than that of the control $(11.04 \mathrm{meq} / \mathrm{L}$ emulsion). Moreover, the same concentration (200 ppm) of catechin and hydrolyzed extract cake did not result in significantly different PVs on day 3. When a high concentration $(1,000 \mathrm{ppm})$ was added to the emulsion,

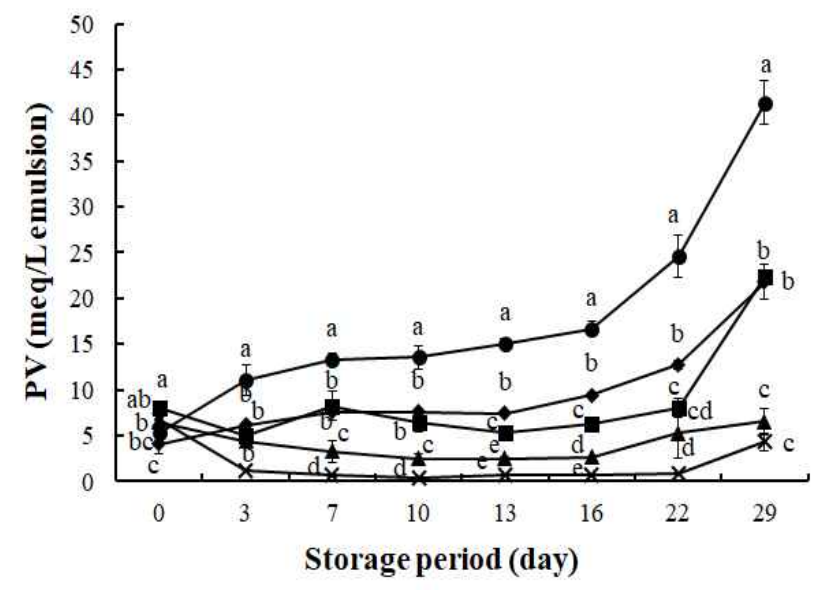

Fig. 2. Effect on formation of lipid hydroperoxides in fish oil-in-water emulsions added with hydrolyzed extract at $200 \mathrm{ppm}$ (অ), $500 \mathrm{ppm}(\mathbf{\Delta})$, and $1,000 \mathrm{ppm}(\times)$ and $200 \mathrm{ppm}$ of catechin $(\checkmark)$ in comparison to the control ().

${ }^{\text {ae }}$ Means with different letters among groups at the same storage period are significantly different at $\mathrm{p}<0.05$ by Duncan's multiple range test $(\mathrm{n}=2)$. hydrolyzed extract showed a significantly reduced PV $(p<0.05)$ during the storage period compared to other emulsions. Patterns of hydroperoxide generation were not distinctively different until day 16 of oxidation.

However, after 16 days of oxidation, PV of the control abruptly increased, and the highest PV (41.4 meq/L emulsion) was observed on day 29. Meanwhile, 200 ppm of catechin prolonged the lag phase of hydroperoxide formation until day 22 (7.99 meq/L emulsion), after which PV increased. Thus, the emulsion with $200 \mathrm{ppm}$ of catechin had a lower PV compared to the emulsion with the same concentration (200 ppm) of hydrolyzed rapeseed cake extract up to 22 days $(\mathrm{p}<0.05)$. Following this, primary oxidation dramatically increased, and similar PVs were observed in the emulsions containing $200 \mathrm{ppm}$ of catechin and hydrolyzed extract after 29 days. Until 22 days of oxidation, the polyphenol catechin showed slightly better antioxidative activity against hydroperoxide formation than hydrolyzed extract when the same amount (200 ppm) was applied. One possible explanation is that the antioxidative potentials of phenols are dependent on structure, and polyphenols are more efficient antioxidants than monophenol, as a second hydroxyl group in the ortho or para position increases antioxidative activity (24).

In this study, hydrolyzed rapeseed cake extract was applied to a fish oil-in-water emulsion. The extract contained a large amount of sinapic acid released from sinapine by $\mathrm{NaOH}$ hydrolysis, and sinapic acid was found to be a better antioxidant and relatively nonpolar compared to sinapine due to esterification of choline. Thiyam et al. (9) reported that sinapic acid exhibited considerable antioxidant activity compared to sinapine on hydroperoxide formation during lipid oxidation. Generally, an oil-in-water emulsion consisting of three parts (lipid droplets, aqueous phase, and oil-water interface) is better protected from oxidation by nonpolar antioxidants than by polar ones, since nonpolar or amphiphilic antioxidants are concentrated at the interface and form a protective membrane around the lipid droplet in the emulsion, whereas relatively polar antioxidants are dissolved in the aqueous phase. Thus, free radicals can be scavenged by lipophilic antioxidants at the interface before they contact the lipid droplet (25).

\section{References}

1. Busch L, Gunter V, Mentele T, Tachikawa M, Tanaka 
K (1994) Socializing nature: technoscience and the transformation of rapeseed into canola. Crop Sci, 34, 607-614

2. Bell JM (1984) Nutrients and toxicants in rapeseed meal: a review. J Anim Sci, 58, 996-1010

3. Lajolo FM, Lanfer Marquez UM, Filisetti-Cozzi TMCC, Ian McGregor D (1991) Chemical composition and toxic compounds in rapeseed (Brassica napus, L.) cultivars grown in Brazil. J Agric Food Chem, 39, 1933-1937

4. Lin L, Allemekinders H, Dansby A, Campbell L, Durance-Tod S, Berger A, Jones PJH (2013) Evidence of health benefits of canola oil. Nutr Rev, 71, 370-385

5. Khatteb RY, Arntfield SD (2009) Functional properties of raw and processed canola meal. LWT-Food Sci Technol, 42, 1119-1124

6. Amarowicz R, Raab B, Shahidi F (2003) Antioxidant activity of phenolic fractions of rapeseed. J Food Lipids, 10, 51-62

7. Khattab R, Eskin M, Aliani M, Thiyam U (2010) Determination of sinapic acid derivatives in canola extracts using high-performance liquid chromatography. J Am Oil Chem Soc, 87, 147-155

8. Thiyam U, Stockmann H, Felde TZ, Schwarz K (2006) Antioxidative effect of the main sinapic acid derivatives from rapeseed and mustard oil by-product. Eur J Lipid Sci Technol, 108, 239-248

9. Thiyam U, Stockmann H, Schwarz K (2006) Antioxidant activity of rapeseed phenolics and their interactions with tocopherol during lipid oxidation. J Am Oil Chem Soc, $84,522-528$

10. Tanaka K, Farooqui AA, Siddiqi NJ, Alhomida AS, Ong WY (2012) Effects of docosahexaenoic acid on neurotransmission. Biomol Ther, 20, 152-157

11. Gan LJ, Yan D, Shin JA, Kim SJ, Hong ST, Lee JH, Sung CK, Lee KT (2012) Oxidative comparison of emulsion systems from fish oil-based structured lipid versus physically blended lipid with purple-fleshed sweet potato (Ipomoea batatas L.) extracts. J Agric Food Chem, 60, 467-475

12. Lee JH, Lee KT, Akoh CC, Chung SK, Kim MR (2006) Antioxidant evaluation and oxidative stability of structured lipids from extravirgin olive oil and conjugated linoleic acid. J Agric Food Chem, 54, 5416-5421

13. Wong CC, Li HB, Cheng KW, Chen F (2006) A systematic survey of antioxidant activity of 30 Chinese medicinal plants using the ferric reducing antioxidant power assay. Food Chem, 97, 705-711

14. Shan B, Cai YZ, Sun M, Corke H (2005) Antioxidant capacity of 26 spice extracts and characterization of their phenolic constituents. J Agric Food Chem, 53, 7749-7759

15. Vuorela S, Meyer AS, Heinonen M (2003) Quantitative analysis of the main phenolics in rapeseed meal and oils processed differently using enzymatic hydrolysis and HPLC. Eur Food Res Technol, 217, 517-523

16. Kim SM, Na MS (2013) A study on skin care effects of rapeseed meal extract. Korean Soc Biotechnol Bioeng J, 28, 177-184

17. Teh SS, Birch EJ (2014) Effect of ultrasonic treatment on the polyphenol content and antioxidant capacity of extract from defatted hemp, flax and canola seed cakes. Ultrason Sonochem, 21, 346-353

18. Wanasundara U, Amarowicz R, Shahidi F (1994) Isolation and identification of an antioxidative component in canola meal. J Agric Food Chem, 42, 1285-1290

19. Lee AY, Hong ST, Jang YS, Lee JH (2014) Lipid composition of Korean rapeseed (Brassica napus L.) cultivar and antioxidant capacity of phenolic extract. J Korean Soc Food Sci Nutr, 43, 1817-1826

20. Sorensen ADM, Friel J, Winkler-Moser JK, Jacobsen C, Huidrom D, Reddy N, Thiyam-Hollander U (2013) Impact of endogenous canola phenolics on the oxidative stability of oil-in-water emulsions. Eur J Lipid Sci Technol, 115, 501-512

21. Kikuzaki H, Hisamoto M, Hirose K, Akiyama K, Taniguchi H (2002) Antioxidant properties of ferulic acid and its related compounds. J Agric Food Chem, 50, 2161-2168

22. McClements DJ, Decker EA (2000) Lipid oxidation in oil-in-water emulsions: Impact of molecular environment on chemical reactions in heterogeneous food systems. J Food Sci, 65, 1270-1282

23. Leopoldini M, Russo N, Toscano M (2011) The molecular basis of working mechanism of natural polyphenolic antioxidants. Food Chem, 125, 288-306

24. Balasundram N, Sundram K, Samman S (2006) Phenolic compounds in plants and agri-industrial by-products: Antioxidant activity, occurrence, and potential uses. Food Chem, 99, 191-203

25. Shahidi F, Zhong Y (2011) Revisiting the polar paradox theory: a critical overview. J Agric Food Chem, 59, 3499-3504 